\title{
OPTIMALISASI PERAN BAHASA INDONESIA DALAM MASYARAKAT EKONOMI ASEAN (MEA) ${ }^{1}$
}

\author{
Sitti Rabiah $^{2}$ \\ Program Studi Bahasa dan Sastra Indonesia \\ Fakultas Sastra \\ Universitas Muslim Indonesia
}

\begin{abstract}
Abstrak
Masyarakat Ekonomi ASEAN (ASEAN Economic Community) merupakan salah satu pilar dari Masyarakat ASEAN yang telah dimulai pemberlakuannya pada 31 Desember 2015. Efektif mulai 1 Januari 2016, Indonesia telah memulai era baru dalam Masyarakat Ekonomi ASEAN (MEA) yang berimplikasi terhadap berbagai aspek, salah satunya membuka kran pekerja asing dari negara-negara anggota ASEAN ke Indonesia. Pemberlakuan MEA di Indonesia harus disikapi secara positif, perspektif yang dapat digunakan yakni menjadikan MEA sebagai sarana mempromosikan bahasa Indonesia kepada pekerja asing di Indonesia. Kebutuhan untuk berkomunikasi dengan 250 juta jiwa rakyat Indonesia tentunya menjadi agenda prioritas bagi para pekerja asing untuk mempelajari bahasa Indonesia agar bisa membaur dengan masyarakat. Sejak awal kehadirannya, bahasa Indonesia telah membuktikan mampu mempersatukan rakyat Indonesia yang terdiri dari berbagai suku dan bahasa daerah yang beragam. Sehingga bahasa Indonesia di era MEA tentunya dapat semakin berkembang dengan semakin banyaknya orang-orang mempelajarinya. Instrumen untuk mengoptimalkan peran bahasa Indonesia dalam MEA yakni penguatan peran pengajar Bahasa Indonesia untuk Penutur Asing (BIPA) dan sosialisasi meluas mengenai Uji Kompetensi Bahasa Indonesia (UKBI). Kedua instrumen ini perlu didukung secara penuh oleh pemerintah melalui instansi terkait agar visi bahasa Indonesia sebagai bahasa internasional dapat terintegrasi dengan MEA.
\end{abstract}

Kata Kunci: Optimalisasi, Peran, Bahasa Indonesia, Masyarakat Ekonomi ASEAN

\begin{abstract}
ASEAN Economic Community (AEC) is one of the pillars of the ASEAN Community which has begun its entry into force on December 31, 2015. Effective on January 1, 2016, Indonesia has embarked on a new era in the AEC, which has implications for various aspects, one of them open the tap of foreign workers from ASEAN member countries to Indonesia. Enforcement of AEC in Indonesia should be addressed in a

\footnotetext{
${ }^{1}$ Makalah telah dipresentasikan dalam Musyawarah Nasional III dan Seminar Nasional Asosiasi Program Studi Bahasa dan Sastra Indonesia (APROBSI) yang diselenggarakan oleh APROBSI bekerjasama dengan Jurusan Bahasa dan Sastra Indonesia Universitas Negeri Makassar pada 29-30 April 2016 di Makassar, Indonesia.

2 (D) https:// orcid.org/ 0000-0002-1690-0025. Kontak penulis: sitti.rabiah@umi.ac.id / sittirabiah25@gmail.com
} 
positive perspective. The perspective can be used which makes the AEC as a tools to promote Indonesian languages for foreign workers in Indonesia. The need to communicate with 250 million people of Indonesia must become a priority agenda for foreign workers to learn Indonesian language to be integrated into society. Since the beginning of its presence, Indonesian has proved able to unite the people of Indonesia, which consists of various ethnic and diverse regional languages. Then, Indonesian languages in the AEC can certainly growing as more people learn it. Instruments to optimize the role of Indonesian languages in the AEC namely strengthening the role of the teachers of Indonesian Languages for Foreign Language Speakers (BIPA) and the dissemination of the Indonesian Languages Competency Test (UKBI). Both of these instruments need to be fully supported by the government through relevant agencies so that the vision of the Indonesian language as an international language can be integrated with the AEC.

Keywords: Optimalization, Roles, Indonesian Language, ASEAN Economic Community

\section{Pendahuluan}

Indonesia telah memulai era baru bersama negara-negara di kawasan Asia Tenggara yang tergabung dalam The Association of Southeast Asian Nations (ASEAN) / Perhimpunan Bangsa-Bangsa Asia Tenggara (Perbara) yakni diberlakukannya era ASEAN Community / Masyarakat ASEAN yang mulai diberlakukan 31 Desember 2015 atau efektif dimulai 1 Januari 2016. Masyarakat ASEAN terdiri atas tiga pilar yakni: Masyarakat Ekonomi ASEAN (MEA/AEC), Masyarakat, Masyarakat Politik dan Keamanan ASEAN (MPKA/APSC) dan Masyarakat Sosial dan Budaya ASEAN (MSBA/ASCC). Ketiga pilar ini membawa implikasi bagi Indonesia, namun yang menjadi arus utama dalam pembicaraan di kalangan akademisi dan praktisi yakni MEA.

Salah satu implikasi pemberlakuan MEA di Indonesia yakni kran pekerja asing dari negara-negara anggota ASEAN semakin terbuka. Namun demikian, implikasi yang ditimbulkan patut direspon secara positif oleh kalangan akademisi bahasa Indonesia yang melihat masuknya pekerja asing sebagai peluang bukan sebagai ancaman. Perspektif yang dapat digunakan yakni menjadikan MEA sebagai sarana mempromosikan bahasa Indonesia kepada pekerja asing yang telah bekerja di Indonesia, maupun yang akan bekerja di Indonesia melalui kebijakan kebahasaan yang tepat dan efektif.

Hal ini dilakukan sebagai upaya mengoptimalkan peran bahasa Indonesia dalam masyarakat ASEAN, sehingga bahasa Indonesia menjadi tuan rumah di negara sendiri, demikian juga dengan pekerja Indonesianya. Makalah ini akan mengulas lebih lanjut langkah-langkah yang dapat dilakukan dengan mempertimbangkan aspek-aspek strategis yang dimiliki bahasa Indonesia.

\section{Bahasa Indonesia sebagai Bahasa Nasional Menuju Bahasa Internasional}

Sejarah bangsa Indonesia telah menempatkan bahasa Indonesia pada kedudukan yang vital salah satunya sebagai bahasa persatuan, atau bahasa nasional. Kedudukan ini 
dimiliki oleh bahasa Indonesia sejak dicetuskannya sumpah pemuda pada tanggal 28 Oktober 1928 dan dihadapkan dengan kenyataan bahwa bahasa Melayu yang mendasari bahasa Indonesia itu, telah dipakai sebagai lingua franca selama berabad-abad sebelumnya di seluruh kawasan Indonesia. (Alwi dan Sugono, 2011b:5)

Bahasa Indonesia dalam peristiwa sumpah pemuda 1928 telah dikukuhkan kehadirannya sebagai bahasa yang demokratis, yang tidak mencerminkan status stratifikasi sosial pemakainya. Oleh karena itu bahasa Indonesia dapat diterima dan dengan mudah dipelajari oleh generasi muda bangsa dari seluruh kelompok etnik yang juga memiliki bahasa daerah yang beranekaragam.

Di dalam kedudukannya sebagai bahasa nasional, bahasa Indonesia berfungsi sebagai (1) lambang kebangaan nasional, (2) lambang identitas nasional, (3) alat pemersatu berbagai kelompok etnik yang berbeda latar belakang sosial budaya dan bahasanya, dan (4) alat perhubungan antarbudaya serta antardaerah. Selain berkedudukan sebagai bahasa nasional, bahasa Indonesia juga berkedudukan sebagai bahasa negara, sesuai dengan ketentuan yang tertera di dalam Undang-Undang Dasar 1945, Bab XV, Pasal 36: Bahasa negara ialah bahasa Indonesia.

UU No. 24 Tahun 2009 tentang Bendera, Bahasa dan Lambang Negara serta Lagu Kebangsaan dalam bagian pertimbangan menyatakan bahwa: bahasa Indonesia sebagai bahasa negara merupakan sarana pemersatu, identitas dan wujud eksistensi bangsa yang menjadi simbol kedaulatan dan kehormatan negara sebagaimana diamanatkan dalam Undang-Undang Dasar Negara Republik Indonesia Tahun 1945. Bahasa Indonesia juga merupakan manifestasi kebudayaan yang berakar pada sejarah perjuangan bangsa, kesatuan dalam keragaman budaya, dan kesamaan dalam mewujudkan cita-cita bangsa dan Negara Kesatuan Republik Indonesia.

Di dalam kedudukannya sebagai bahasa negara, bahasa Indonesia berfungsi sebagai (1) bahasa resmi kenegaraan, (2) bahasa pengantar resmi di lembaga pendidikan, (3) bahasa resmi di dalam perhubungan dalam tingkat nasional, (4) bahasa resmi untuk pengembangan kebudayaan nasional, (5) sarana pengembangan ilmu pengetahuan dan teknologi modern, (6) bahasa media massa, (7) pendukung sastra Indonesia, dan (8) pemerkaya bahasa dan sastra daerah. (Alwi dan Sugono, 2011b:5)

Selain fungsi bahasa Indonesia sebagai bahasa nasional dan bahasa negara, pemerintah dalam Pasal 44 UU No. 24/2009 juga berkomitmen untuk meningkatkan fungsi bahasa Indonesia menjadi bahasa internasional secara bertahap, sistematis, dan berkelanjutan. Peningkatan fungsi Bahasa Indonesia menjadi bahasa internasional ini dikoordinasi oleh lembaga kebahasaan dan ketentuan lebih lanjut diatur dalam Peraturan Pemerintah. Kebijakan ini menjadi landasan bagi lembaga kebahasaan dalam hal ini Badan Bahasa di tingkat Pusat dan Balai Bahasa di daerah, serta akademisi bahasa Indonesia di perguruan tinggi untuk mendorong upaya bahasa Indonesia menjadi bahasa Internasional.

Kongres Bahasa Indonesia X pada Oktober 2013 yang mengangkat tema "Penguatan Bahasa Indonesia di Dunia Internasional" merekomendasikan poin-poin penting yang mengungkap strategi bahasa Indonesia menuju bahasa Internasional dan 
posisi bahasa Indonesia di ASEAN. Secara umum poin-poin tersebut membahas antara lain: peningkatan kualitas dan kuantitas kerjasama dengan berbagai pihak luar negeri untuk menginternasionalkan bahasa Indonesia di tingkat komunitas ASEAN maupun dunia internasional dengan dukungan sumber daya yang maksimal, pelibatan seluruh komponen bangsa untuk menginternasionalkan bahasa Indonesia melalui "diplomasi total", pemerintah memperkuat peran Bahasa Indonesia untuk Penutur Asing (BIPA) dengan mengembangkan kurikulum, bahan ajar dan silabus yang standar, termasuk bagi Masyarakat ASEAN dan penerapan Uji Kemahiran Berbahasa Indonesia (UKBI) sebagai "paspor bahasa" bagi tenaga kerja asing di Indonesia".

Proses bahasa Indonesia menjadi bahasa nasional (bahasa negara) telah melalui proses panjang di mulai dengan peristiwa Sumpah Pemuda pada tahun 1928, kemudian semangat ini diadopsi ke dalam Undang-Undang Dasar Negara Kesatuan Republik Indonesia tahun 1945 dan dibuatkan regulasi khusus dalam UU No. 24 Tahun 2009 tentang Bendera, Bahasa dan Lambang Negara serta Lagu Kebangsaan. Kemudian bahasa Indonesia menuju bahasa internasional telah mulai digagas dengan menghadirkan bagian khusus dalam UU No. 24/2009 yang membahas tentang peningkatan fungsi bahasa Indonesia menjadi bahasa internasional. Kemudian ditindaklanjuti menjadi tema agenda lima tahunan dalam Kongres Bahasa Indonesia X serta menjadi isu strategis dalam Rembuknas Pendidikan dan Kebudayaan Tahun 2016 pada minggu keempat Februari 2016. Hal-hal yang dipaparkan di atas merupakan dasar pemahaman untuk mendorong bahasa Indonesia menuju bahasa internasional dan menyusun strategi untuk mengoptimalkan peran bahasa Indonesia dalam Masyarakat Ekonomi ASEAN.

\section{Sejarah Singkat ASEAN dan MEA}

Menilik sejarah ASEAN (The Association of Southeast Asian Nations) sebagai organisasi regional di kawasan Asia Tenggara yang terdiri dari 10 negara yang didirikan 8 Agustus 1967 oleh Indonesia, Malaysia, Filipina, Singapura, dan Thailand. Sejak pendiriannya anggota ASEAN telah meliputi Brunei Darussalam, Myanmar, Kamboja, Laos, dan Vietnam. Dalam dokumen pendirian ASEAN (The ASEAN Declaration/The Bangkok Declaration) menyebutkan bahwa maksud dan tujuan pertama didirikannya ASEAN adalah untuk mempercepat pembangunan ekonomi, kemajuan sosial, dan perkembangan kejayaan di kawasan guna memperkuat dasar bagi sebuah komunitas yang sejahtera dan damai di Asia Tenggara. Adapun maksud dan tujuan kedua untuk meningkatkan perdamaian dan stabilitas kawasan.

Dalam rangka mewujudkan tujuan ASEAN tersebut, mulai 31 Desember 2015 Indonesia bersama 9 negara anggota ASEAN lainnya yakni: Brunei Darussalam, Filipina, Malaysia, Singapura, Thailand, Vietnam, Laos, Myanmar dan Kamboja akan mulai memasuki babak baru dalam kerangka ASEAN Community. Komunitas ini terdiri atas tiga pilar yakni: ASEAN Economic Community (AEC)/Masyarakat Ekonomi ASEAN (MEA), ASEAN Political and Security Community (APSC)/Masyarakat 
Politik dan Keamanan ASEAN (MPKA) dan ASEAN Socio-Cultural Community (ASCC)/ Masyarakat Sosial dan Budaya ASEAN (MSBA).

Integrasi masyarakat ASEAN bagi Indonesia dapat menjadi peluang sekaligus tantangan. Oleh karena itu, analisis mendalam terhadap langkah-langkah untuk mengoptimalkan peran bahasa Indonesia dalam Masyarakat Ekonomi ASEAN (MEA) memerlukan pendekatan interdisipliner, selain pendekatan kebahasaan, tetapi tidak menutup kemungkinan bahwa ilmuwan dari bidang ilmu lainnya turut berkontribusi untuk memberikan masukan-masukan konstruktif bagi pengembangan bahasa Indonesia di dunia internasional. Identifikasi mutakhir terhadap potensi yang ada dapat memperbesar manfaat dan keuntungan yang diperoleh oleh Indonesia, serta meminimalisasi kerugian yang dapat timbul akibat ketidakpahaman Indonesia atas konsekuensi kesepakatan tersebut.

\section{Optimalisasi Peran Bahasa Indonesia dalam MEA}

Implikasi dimulainya era MEA yang efektif diberlakukan 31 Desember 2015 di seluruh negara anggota ASEAN juga dirasakan Indonesia. Kekhawatiran yang timbul di masyarakat atas pemberlakuan MEA, salah satunya membuka kran pekerja asing masuk ke Indonesia, sehingga lapangan pekerjaan semakin berkurang dan pengangguran semakin meningkat. Jika dilihat dari perspektif kebahasaan, masuknya pekerja asing di Indonesia dengan membawa bahasa dari negara asalnya tentu mengancam eksistensi bahasa Indonesia di tengah-tengah masyarakat.

Namun demikian, hal ini patut disikapi secara positif. Perspektif yang digunakan yakni menjadikan MEA sebagai sarana mempromosikan bahasa Indonesia kepada pekerja asing di Indonesia. Hal ini didasarkan pada kebutuhan para pekerja asing untuk berkomunikasi dengan 250 juta jiwa rakyat Indonesia agar bisa membaur dengan masyarakat, sehingga menjadi agenda prioritas mereka. Instrumen yang ditawarkan untuk mengoptimalkan peran bahasa Indonesia dalam MEA yakni penguatan peran pengajar Bahasa Indonesia untuk Penutur Asing (BIPA) dan sosialisasi meluas mengenai Uji Kompetensi Bahasa Indonesia (UKBI).

Bahasa Indonesia untuk Penutur Asing (BIPA) merupakan program pembelajaran keterampilan berbahasa Indonesia (berbicara, menulis, membaca, dan mendengarkan) bagi penutur asing. Kepala Badan Pengembangan dan Pembinaan Bahasa Kementerian Pendidikan dan Kebudayaan dikutip Kompas (2013) menyatakan bahwa salah satu tugas (dan) fungsi badan bahasa (Kemdikbud), yaitu menginternasionalisasikan bahasa Indonesia. Fungsi ini tentu terkait dengan ikhtiar kita mengajar bahasa Indonesia pada penutur asing.

Perkembangan bahasa Indonesia di luar negeri sangat terlihat adanya keragaman motivasi sosial dan politik dengan keterlibatan pemerintah, lembaga swasta, universitas, kerjasama internasional, orientasi pengajaran, penyediaan materi ajar, dan manajemen pelatihan. Perkembangan BIPA di luar negeri ini khususnya di Korea, Australia, Amerika Serikat, Jerman, dan Rusia. Akan tetapi, sebagian besar pemelajar BIPA adalah dari Korea. Sifat pembelajaran BIPA yang melibatkan penutur asing ini 
membuat kebanyakan kegiatan pembelajaran BIPA berlangsung di luar Indonesia. Minat penutur asing untuk mempelajari Bahasa Indonesia memang semakin meningkat. Hal ini dapat dilihat dari semakin banyaknya orang asing yang ingin mempelajari Bahasa Indonesia dengan berbagai tujuan, seperti tujuan politik, ekonomi, perdagangan, seni-budaya, wisata, maupun pendidikan. (Robita: 2012)

Minat yang besar terhadap program BIPA di dalam maupun di luar negeri merupakan kekuatan bahasa Indonesia untuk semakin memperkenalkan bahasa ini kepada orang asing, utamanya masyarakat ASEAN yang terdiri dari 600 juta jiwa yang bergerak di kawasan Asia Tenggara. Selain menjangkau negara-negara besar, BIPA juga perlu didorong untuk dipelajari oleh masyarakat ASEAN dengan melakukan kerjasama yang intensif antar-kampus, lembaga bahasa maupun perwakilan Indonesia yang berada di kawasan Asia Tenggara.

Para pengajar BIPA di Indonesia saat ini sudah mempunyai organisasi profesi yang disebut Asosiasi Pengajar dan Pegiat Bahasa Indonesia untuk Penutur Asing atau APPBIPA. APPBIPA mempunyai visi untuk menjadi organisasi profesi yang mandiri dan profesional dalam bidang pengajaran dan penyelenggaraan BIPA demi mewujudkan bahasa Indonesia sebagai sarana komunikasi internasional; dan misi membantu pemerintah dalam meningkatkan fungsi bahasa Indonesia menjadi bahasa internasional, mengembangkan dan meningkatkan profesionalisme pengajar dan pegiat BIPA dan meningkatkan citra Indonesia melalui pengajaran BIPA. Dukungan organisasi profesi seperti APPBIPA tentu semakin menguatkan visi bahasa Indonesia sebagai bahasa internasional, khususnya peran bahasa Indonesia dalam MEA.

Uji Kompetensi Bahasa Indonesia (UKBI) merupakan salah satu instrumen yang juga menunjang visi bahasa Indonesia sebagai bahasa internasional, khususnya perannya dalam MEA. UKBI adalah uji kemahiran (proficiency test) untuk mengukur kemahiran berbahasa seseorang dalam berkomunikasi dengan menggunakan bahasa Indonesia, baik penutur Indonesia maupun penutur asing. UKBI meliputi lima seksi, yaitu Seksi I (Mendengarkan), Seksi II (Merespons Kaidah), Seksi III (Membaca), Seksi IV (Menulis), dan Seksi V (Berbicara).

UKBI dikembangkan oleh Pusat Bahasa Departemen Pendidikan Nasional sejak tahun 1997, sebagai rekomendasi Kongres Bahasa Indonesia III, dan diresmikan penggunaannya oleh Menteri Pendidikan Nasional, Dr. Bambang Sudibyo pada tahun 2006. Di masa yang akan datang uji kemahiran ini akan digunakan sebagai instrumen penerimaan pegawai dan syarat bagi orang asing yang ingin belajar dan bekerja di Indonesia, seperti halnya TOEFL dalam Bahasa Inggris.

Dalam konteks ASEAN, UKBI dapat digunakan sebagai instrumen bagi masuknya pekerja asing melalui Mutual Recognition Agreements (MRAs) yang telah disepakati oleh negara-negara anggota ASEAN. Dikutip dari website Kementerian Ketenagakerjaan (Kemenaker) pemerintah Indonesia memberikan perhatian khusus terhadap 8 profesi yang menjadi prioritas yakni akuntansi, teknik, survei, arsitektur, keperawatan, kesehatan, perawatan gigi dan pariwisata. (Kemenaker, 2014) 
Pekerja migran ASEAN yang berada pada 8 profesi yang telah disepakati ini patut untuk mempelajari bahasa di negara tujuan, utamanya pekerja migran ASEAN yang masuk ke Indonesia. Profesi perawat, tenaga kesehatan, dokter gigi dan pariwisata merupakan profesi yang memerlukan kecakapan bahasa Indonesia, dikarenakan profesi ini bersentuhan langsung dengan masyarakat dan interaksi juga terjadi secara langsung. Sehingga UKBI dapat digunakan sebagai salah satu prasyarat untuk bekerja di Indonesia. Walaupun demikian profesi akuntan, teknisi, survei dan arsitektur tetap memerlukan kecakapan berbahasa Indonesia yang cukup, dikarenakan lingkungan kerja yang dihadapi menggunakan bahasa Indonesia dalam berkomunikasi dan memberikan instruksi kerja.

\section{Penutup}

Bahasa Indonesia dalam MEA patut disikapi dengan bijak. Bahasa Indonesia dapat melakukan promosi terbuka kepada siapapun pekerja migran ASEAN yang tertarik bekerja di Indonesia. Pembukaan lembaga BIPA di negara-negara anggota ASEAN tentunya semakin mengukuhkan peran bahasa Indonesia dalam MEA.

Profesi yang dibolehkan untuk bergerak secara bebas di negara-negara anggota ASEAN juga memerlukan kecakapan tertentu dalam bahasa Indonesia hal ini bergantung pada intensitas komunikasi yang diperlukan. Misalnya profesi yang berinteraksi langsung dengan masyarakat memerlukan kecakapan pada kategori mahir, sedangkan profesi yang berinteraksi terbatas di lingkungan kerja memerlukan kecapakan pada kategori cukup.

\section{References}

Abidin, Y dan Sri, A. 2013. Pembelajaran BIPA (Bahasa Indonesia bagi Penutur Asing). Bandung: CV. Rizqi.

Alwi, Hasan, dan Dendy Sugono (ed.). 2011. Politik Bahasa. Jakarta: Badan Pengembangan dan Pembinaan Bahasa Kemdikbud.

ASEAN. 2011. Roadmap for an ASEAN Community 2009-2015. Jakarta: ASEAN Secretariat.

Asosiasi Pengajar dan Pegiat Bahasa Indonesia untuk Penutur Asing. Visi Misi http://appbipa.org/apbipa/visimisi, diakses 7 April 2016.

Badan Pengembangan dan Pembinaan Bahasa. Rekomendasi Kongres Bahasa Indonesia $\mathrm{X}-$

http://badanbahasa.kemdikbud.go.id/lamanbahasa/content/rekomendasi-kongresbahasa-indonesia-x, diakses 7 April 2016.

Cipto, Bambang. 2007. Hubungan Internasional di Asia Tenggara. Pustaka Pelajar: Yogyakarta. 
Irsan, Abdul. 2010. Peluang dan Tantangan Diplomasi Indonesia. Jakarta: Himmah Media.

Kementerian Ketenagakerjaan. Hadapi MEA 2015 Pemerintah Fokus Siapkan 8 Profesi Prioritas - http://ppid.depnakertrans.go.id/hadapi-mea-2015-pemerintah-fokus-siapkan8-profesi-prioritas, diakses 7 April 2016.

Kompas. BIPA Tingkatkan Fungsi Bahasa Indonesia menjadi Bahasa Internasional http://lipsus.kompas.com/kemdikbud/read/2013/10/23/1253102/BIPA.Tingkatkan. Fungsi.Bahasa.Indonesia.Menjadi.Bahasa.Internasional, diakses 7 April 2016.

Rabiah, Sitti. 2012. Language as a Tool for Communication and Cultural Reality Discloser. Dipresentasikan dalam $1^{\text {st }}$ International Conference on Media, Communication and Culture. Yogyakarta: Universitas Muhammadiyah Yogyakarta and Universiti Sains Malaysia. doi: 10.31227/osf.io/nw94m

Rabiah, Sitti. 2013. "Bahasa Indonesia di Perguruan Tinggi sebagai Wahana Pembangun Karakter (Jati Diri) dan Kreatifitas Mahasiswa: Studi Kasus di Universitas Muslim Indonesia, Makassar". Makalah. Kongres Bahasa Indonesia X, Badan Pengembangan dan Pembinaan Bahasa. doi: 10.31227/osf.io/mqe8y

Warsito, Tulus, dan Wahyuni Kartikasari. 2007. Diplomasi Kebudayaan: Konsep dan Relevansi bagi Negara Berkembang Studi Kasus Indonesia. Yogyakarta: Penerbit Ombak.

Zulfikar, Achmad. 2013. Bahasa Indonesia sebagai Embrio Bahasa ASEAN: Peluang dan Tantangan Menuju ASEAN Community 2015. Makalah. Disajikan pada Kongres Bahasa Indonesia X di Hotel Grand Sahid Jakarta, 28-31 Oktober 2013.

Zulfikar, Achmad. 2015. Mapping the Position of Indonesian Migrant Workers towards ASEAN Economic Community 2015. Makalah. Disajikan pada $1^{\text {st }}$ International Conference of Journal Government and Politics di Universitas Muhammadiyah Yogyakarta, 14 Maret 2015. doi: 10.31219/osf.io/5cefw 